\title{
OTIMIZAÇÃO DO PROCESSO DE PRODUÇÃO DE OLEATO DE ETILA VIA CATALISE ENZIMÁTICA IMOBILIZADA EM SITU EM POLIURETANO EM SISTEMA LIVRE DE SOLVENTE
}

\author{
N. L. D. NYARI ${ }^{1}$, A. R. PAULAZZI ${ }^{1}$, R. V. ZAMADEI ${ }^{1}$, A. M. M. FICANHA ${ }^{1}$, A. \\ ANTUNES ${ }^{1}$, K. LEVANDOSKI ${ }^{1}$, J. ZENI ${ }^{1}$, R. M. DALLAGO ${ }^{1}$ \\ ${ }^{1}$ Universidade Regional Integrada do Alto Uruguai e Missões - URI- Erechim - RS, \\ Departamento de Engenharia de Alimentos \\ E-mail para contato: nadialigianara@hotmail.com
}

\begin{abstract}
RESUMO - A otimização do processo de produção de oleato de etila via catalise enzimática, empregando a lipase de Candida antarctica B imobilizada em situ em poliuretano em sistema livre de solvente. A metodologia de delineamento de experimentos $2^{2}$ para as variáveis estudadas foram à concentração do imobilizado $(0,0295-0,1705 \mathrm{~g})$ e temperatura $\left(18,85-61,15^{\circ} \mathrm{C}\right)$. Apresentando resultados significativos para produção de oleato de etila em 40 min de reação, utilizando $\left(40,0^{\circ} \mathrm{C}-0,0295 \mathrm{~g}\right)$ a atividade de estereficação de $2017,12 \mathrm{U} / \mathrm{g}$ e $456,28 \%$ de rendimento, enquanto a conversão foi de $48,67 \%\left(61,15^{\circ} \mathrm{C}\right.$ e $\left.0,1 \mathrm{~g}\right)$. Nestas condições o imobilizado foi submetido a 22 ciclos operacionais de reutilização, apresentando $51 \%$ de atividade residual em relação a inicial. Sendo assim os resultados obtidos apresentam boas perspectivas para aplicação em síntese orgânica, em reações que envolvem a formação de ésteres e a possibilidade de ser reutilizado sucessivamente, gerando menos custos na aplicação industrial.
\end{abstract}

\section{INTRODUÇÃO}

Ésteres são importantes compostos orgânicos, obtidos por síntese química, enzimática ou extraídos através da utilização de solventes. Dentre essas aplicações os ésteres tem se destacado principalmente na indústria em produtos alimentícios, farmacêuticos e cosméticos. (Gandhi et al., 1995; Abbas e Comeau, 2003). Sua síntese é geralmente lenta e necessita da utilização de catalisador químico adequado a fim de se tornarem viáveis economicamente. Os processos catalíticos tradicionais envolvem ácidos (como ácido oleico) e bases (como hidróxido de sódio) como aceleradores da reação (Morrison e Boyd, 1966). Porém, aos poucos tem sido substituído por catalisadores enzimáticos, visto que essas apresentam benefícios e condições suaves de reação (temperatura, pressão e $\mathrm{pH}$ ), estabilidade a solventes, especificidade e estabilidade operacional (Gabelan, 1994). A motivação está relacionada à alta aceitabilidade comercial, pois caracteriza o produto como natural, sendo mais específica e viável economicamente (Abbas e Comeau, 2003; Hasan et al., 2006).

A utilização de lipases (triacilglicerol acil hidrolases, E.C. 3.1.1.3), principalmente a lipase B de Candida antarctica (CALB) tem atraído muita atenção dos pesquisadores devido a sua alta estabilidade, capacidade de atuação sobre vários substratos e tolerância em meios 
não aquosos, além de ser estável em pHs ácidos, tem sido citada em diversos trabalhos relacionados à obtenção de ésteres (Abbas e Comeau, 2003; Rajendrani et al., 2009; Dalla Rosa et al., 2010; Skoronski et al.1, 2010; Dheeman et al., 2011; Gumel et al., 2011). Considerando que o custo da enzima é um fator determinante da viabilidade econômica, a principal vantagem para reduzir o custo é melhorar a viabilidade econômica dos processos é imobilizar, além de torna-las mais estáveis no meio orgânico, facilitando sua recuperação e posterior reutilização (Dalla Rosa et al., 2010; Jun et al., 2013). Sendo assim o principal objetivo deste trabalho foi avaliar a imobilização da lipase B de Candida antarctica B em situ em Poliuretano (PU) na de produção de oleato de etila em via ácido oleico e álcool etílico em sistema livre de solvente orgânico.

\section{MATERIAIS E MÉTODOS}

A enzima utilizada nesta pesquisa foi a lipase de Candida antarctica B (Novozyme NZL-102-LYO-HQ) e os monômeros comerciais Poliol e Isocianato (Empresa Flexível Poliuretanos - Mannes). Os solventes foram acetona (FMaia), ácido Oléico (Vetec), álcool Etílico (Merck) e hidróxido de Sódio (Nuclear).

\subsection{Imobilização}

O procedimento de imobilização da enzima CAL B imobilizada em situ em espuma rígida de poliuretano (PU) foi realizada na concentração pré-estabelecida (60/40\%) descrita por Nyari (2013) onde são adicionadas $10 \%$ da enzima diluída ao monômero (Poliol), homogeneizado e em seguida adicionado o isocianato, após 5 min (etapa de polimerização) o derivado imobilizado foi mantido por 24 horas em dessecador e posterior medida da atividade por esterificação e seu rendimento.

\subsection{Otimização do Processo de Produção de Oleato de Etila}

Inicialmente foi realizado um delineamento fatorial completo $2^{2}$ com triplicata do ponto central, totalizando 11 experimentos, fixando a razão molar dos substratos em $5 \mathrm{~g}$ (ácido oleico/álcool etílico) em (1:1), o tempo em 40 min e a rotação em $160 \mathrm{rpm}$ e variando a concentração de enzima $(0,0295-0,1705 \mathrm{~g})$ e a temperatura de reação $\left(18,85-61,15^{\circ} \mathrm{C}\right)$, todos os experimentos foram realizados em triplicata e um branco sem a adição de enzima correspondente a cada temperatura (Ferraz et al., 2014). Depois de otimizados as variáveis de produção de oleato de etila foram realizadas o estudo dos ciclos operacionais da lipase imobilizada, após cada ciclo de medida de atividade a lipase imobilizada era submetida a um novo processo sem lavagem, retirado apenas o excesso por meio de centrifugação (2000 rpm) por $5 \mathrm{~min}$, sendo realizado todos em triplicata, repetidos sucessivamente até obtermos resultados inferiores a $50 \%$ da atividade inicial.

\subsection{Determinações analíticas}

A reação de síntese de ésteres de oleato de etila foi determinada de acordo com a atividade enzimática via esterificação e rendimento foi realizada utilizando alíquotas de 500 $\mu \mathrm{L}$ do meio reacional (em triplicata) e adicionadas $15 \mathrm{~mL}$ de uma solução de acetona-etanol $(1: 1)(\mathrm{v} / \mathrm{v})$ e posteriormente titulada com $\mathrm{NaOH} 0,05 \mathrm{M}$. Uma unidade de atividade 
enzimática foi definida como a quantidade de enzima que consome $1 \mu \mathrm{mol}$ de ácido graxo por minuto, nas condições do ensaio, sendo calculada utilizando metodologia de Ferraz et al. (2014). Enquanto para calcular o rendimento da imobilização (Brígida et al., 2010) foi considerada a atividade total da enzima livre em solução (a qual considera o volume de extrato enzimático empregado no ensaio de imobilização) e a atividade total do imobilizado (o qual considera a massa total de imobilizado produzido). A quantificação via conversão por cromatografia gasosa em equipamento Shimadzu GC-2010 equipado com processador de dados. As análises foram realizadas utilizando coluna capilar de sílica fundida INOWAX (30m x 250m i.d.), $0,25 \mathrm{~mm}$ de espessura de filme, detector FID, com a seguinte programação de temperatura: $40-180^{\circ} \mathrm{C}\left(3{ }^{\circ} \mathrm{C} / \mathrm{min}\right), 180-230{ }^{\circ} \mathrm{C}\left(20^{\circ} \mathrm{C} / \mathrm{min}\right), 230{ }^{\circ} \mathrm{C}(20 \mathrm{~min})$, temperatura do injetor $250^{\circ} \mathrm{C}$, detector a $275^{\circ} \mathrm{C}$, modo de injeção split, razão de split $1: 100$, gás de arraste $\mathrm{H}_{2}(56 \mathrm{kPa})$, volume injetado $0,100 \mathrm{~mL}$ de amostra diluída em diclorometano (1:10). A determinação da conversão das reações é feita acompanhando a redução da área do sinal do agente limitante (Paroul et al., 2011). A análise estatística de variância, foi realizada pelo teste de Tukey foi aplicada para a análise estatística dos dados obtidos, sendo tratados com o auxílio do programa software Statistica ${ }^{\circledR} 8.0$ (Statsoft Inc).

\section{RESULTADOS E DISCUSSÕES}

Primeiramente foi realizado um estudo do tempo de reação, pois atraves deste agiliza o processo e evita perdas de materiais e solventes como de energia. $\mathrm{O}$ estudo foi realizado variando os tempos de reação de 0 a 60 min, fixando a concentraçao de enzima em $0,0295 \mathrm{~g}$ (livre e imobilizada $(\mathrm{m} / \mathrm{m})), 160 \mathrm{rpm}$, razão molar de acido/alcool $(1: 1)$ e temperatura $\left(40{ }^{\circ} \mathrm{C}\right)$, sendo estes o ponto central do planejamento de experimentos pelo método de estereficação e por conversão. Os resultados obtidos na cinética do tempo de reação de esterificação para a lipase na forma livre foi de 474,14 U/g, já quando a lipase imobilizada em $\mathrm{Pu}$ a atividade foi de $2177,08 \mathrm{U} / \mathrm{g}$ e conversão de 48,64 em 40 min de reação, assim podemos observar que a lipase imobilizada necessita de menos tempo para que a reação ocorra.

\subsection{Otimização do Processo de produção de oleato de etila empregando Lipase Candida antarctica B (CAL B ) Livre e Imobilizada em PU}

A matriz do deliniamento experimental $2^{2}$ completo (codificados e valores reais) com as respostas em termos de conversão de oleato de etila é apresentada na Tabela 1. Analisando os resultados, podemos observar que quando utilizado $0,1 \mathrm{~g}$ da enzima livre, a $40{ }^{\circ} \mathrm{C}$, esta apresentou atividade de estereficação igual a 6583,33 U/g. Já utilizado 0,0295 g da enzima imobilizada em poliuretano apresentou atividade de 5689,66 U/g, rendimento de $356,28 \%$ e conversão de 48,67 \%, utilizando 0,1705 g de enzima sob temperatura de $40{ }^{\circ} \mathrm{C}$. Essa baixa conversao pode estar relacionada ao baixo tempo de reacao que foram de apenas de $40 \mathrm{~min}$, aumentando essa exposicao poderia resultar em resultados mais significativos em termos de producao de oleato de etila.

A análise estatística permitiu a contrução de um modelo ímpirico, o qual é apresentado a atividade de estereficação na (Equação 1) para a lipase livre e para a lipase imobilizada (Equação 2) e de conversão (Equação 3). Esta equação apresenta um modelo codificado de segunda ordem, o qual descreve a atividade de esterificação em função das variáveis independentes analisadas (concentração de enzima imobilizada, temperatura $\left({ }^{\circ} \mathrm{C}\right)$ ), dentro da 
faixa estudada. Atividade de esterificação $(\mathrm{U} / \mathrm{g})$ indica a reação de oleato de etila $(\%) ; \mathrm{X}_{1}=$ concentração de lipase livre e imobilizada e $\mathrm{X}_{2}=$ temperatura $\left({ }^{\circ} \mathrm{C}\right)$.

Ativ. Livre $=6363,09-1194,04 X_{1}-1271,90 X_{1}^{2}+468,60 X 2-1163,71 X_{2}^{2}+419,14 X_{1} X_{2} \quad U / g \quad$ (1)

Ativ. $I m o b=788,67-547,645 X_{1}+102,356 X_{1}{ }^{2}+197,972 X_{2}-142,166 X_{2}^{2}-97,675 X_{1} X_{2} \quad U / g \quad$ (2)

Conversão $=17,7058+11,1656 \mathrm{X}_{1}+12,6268 \mathrm{X}_{1}^{2}+0,9296 \mathrm{X}_{2}+1,525 \mathrm{X}_{2}^{2}+3,7715 \mathrm{X}_{1} \mathrm{X}_{2} \quad(\%)$

Tabela 1 - Matriz do deliamento experimental $2^{2}$ completo com a resposta em termos de atividade enzimatica de estereficação, rendimentos da reação e conversão de Oleato de Etila.

\begin{tabular}{ccccccc}
\hline & $\begin{array}{c}\text { Enzima } \\
(\mathrm{wt} \%)\end{array}$ & $\begin{array}{c}\text { Temperatura } \\
\left({ }^{\circ} \mathrm{C}\right)\end{array}$ & $\begin{array}{c}\text { Enzima } \\
\text { Livre }(\mathrm{U} / \mathrm{g})\end{array}$ & $\begin{array}{c}\text { Enzima } \\
\text { Imobilizada } \\
(\mathrm{U} / \mathrm{g})\end{array}$ & $\begin{array}{c}\text { Rendimento } \\
(\%)\end{array}$ & $\begin{array}{c}\text { Conversão } \\
(\%)\end{array}$ \\
\hline 1 & $-1(0,05)$ & $-1(25)$ & $4635,26 \pm 131,6$ & $840,00 \pm 13,7$ & 181,22 & 13,52 \\
2 & $1(0,15)$ & $-1(25)$ & $1362,51 \pm 71,5$ & $135,19 \pm 96,0$ & 99,22 & 21,16 \\
3 & $-1(0,05)$ & $1(55)$ & $5250,00 \pm 250,0$ & $1310,61 \pm 173,5$ & 249,64 & 27,14 \\
4 & $1(0,015)$ & $1(55)$ & $3653,85 \pm 66,6$ & $215,10 \pm 22,7$ & 58,87 & 46,06 \\
5 & $-1,41(0,0295)$ & $0(40)$ & $5689,66 \pm 149,3$ & $2027,12 \pm 61,0$ & 356,28 & 2,34 \\
6 & $1,41(0,1705)$ & $0(40)$ & $2388,24 \pm 53,0$ & $205,98 \pm 3,9$ & 86,25 & 48,67 \\
7 & $0(0,1)$ & $-1,41(18,85)$ & $3958,33 \pm 72,1$ & $265,68 \pm 11,0$ & 67,12 & 1,77 \\
8 & $0(0,1)$ & $1,41(61,15)$ & $4548,10 \pm 50,5$ & $995,15 \pm 5,8$ & 218,81 & 33,84 \\
9 & $0(0,1)$ & $0(40)$ & $6583,33 \pm 288,6$ & $784,98 \pm 39,5$ & 119,24 & 8,64 \\
10 & $0(0,1)$ & $0(40)$ & $6333,33 \pm 144,3$ & $789,089 \pm 39,5$ & 124,59 & 9,09 \\
11 & $0(0,1)$ & $0(40)$ & $6167,76 \pm 284,8$ & $789,01 \pm 24,5$ & 127,92 & 7,90 \\
\hline
\end{tabular}

A conversão em ésteres varia significativamente com relação ao composto formado, a quantidade de enzima utilizada, e método de imobilização empregado, podendo variar de poucas horas até dias de reação, sendo assim em nosso estudo os resultados de medida de atividade de esterificação foram significativos quando comparados ao da literatura, visto que quando comparados à porcentagem de conversão, não foram tão expressivos, isto deve principalmente ao pouco tempo de reação e da concentração do biocatalisador. De acordo com estudos realizados por Paroul et al. (2010), com o objetivo principal a otimização da produção do geranil propionato num sistema isenta de solvente, utilizando $10 \%$ da lipase imobilizada comercialmente como catalisador (Novozym 435), em uma temperatura de $40{ }^{\circ} \mathrm{C}$, e proporção molar de geraniol e ácido propiônico de 3:1, $150 \mathrm{rpm}$, obtiveram uma conversão de cerca de $93 \%$. Enquanto que a $60{ }^{\circ} \mathrm{C}$ em 6 horas de reação, nas mesmas condições de razão molar e agitação, obtiveram 85,8 \% de conversão em geranil propionato.

Kumar et al. (2004) investigaram a síntese de etil palmitato, utilizando a lipase imobilizada comercial Novozym 435 como catalisador ( $2 \%$ em peso de enzima), proporção molar álcool/ácido de $12: 1$ na temperatura de $55{ }^{\circ} \mathrm{C}$ e $150 \mathrm{rpm}$ em 12 horas de reação e obtiveram cerca de $97 \%$ de conversão. O imobilizado submetido a sucessos ciclos de operacionais de reuso, nas condições ótimas de esterificação e rendimentos, a uma concentração de enzima imobilizada ( $(\%$ em peso $)$ de $(0,295 \mathrm{~g})$ a uma temperatura de $\left(40{ }^{\circ} \mathrm{C}\right)$, 


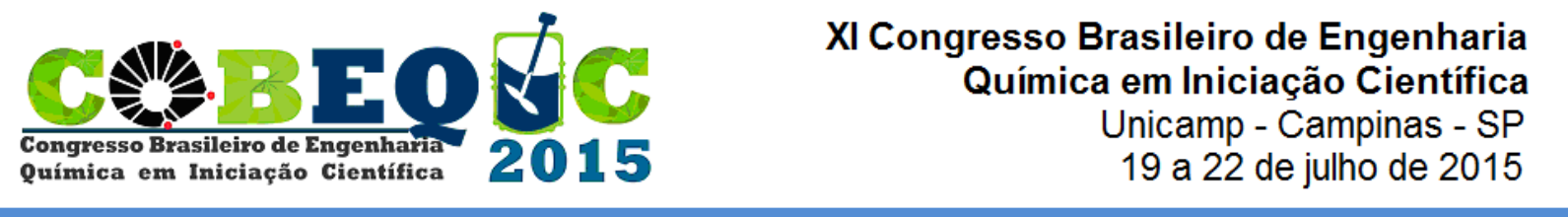

apresentou no decorrer de 22 ciclos contínuos uma atividade residual de $60 \%$ em relação à atividade inicial 1.909,33 U/g (Figura 1).

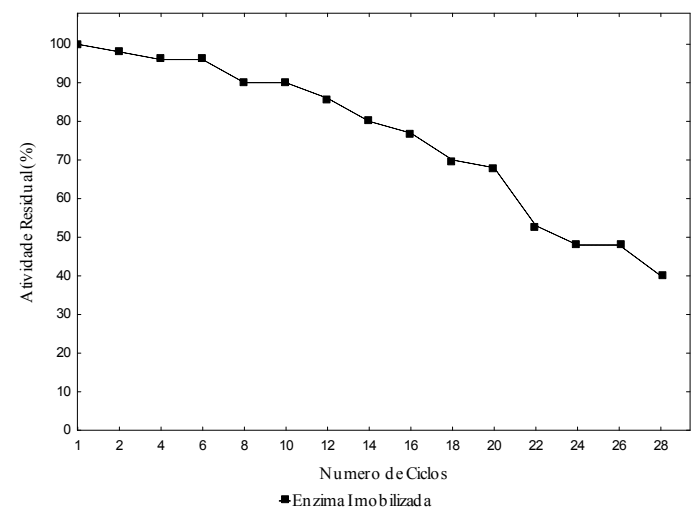

Figura 1 - Avaliação dos ciclos operacionais da lipase CAL B Imobilizada em PU na produção de oleato de etila via esterificação enzimática.

Estes resultados mostram se superiores ao encontrados na literatura. Guncheva et al. (2011), a lipase de Candida rugosa imobilizada em poliuretano, mantém $80 \%$ de sua atividade inicial após 15 ciclos, sendo aplicado na esterificação de ácido palmítico com álcool etílico.

\section{CONCLUSÕES}

Os resultados obtidos demonstraram que a imobilização da lipase de Candida antarctica B (Novozymes) imobilizada em situ em poliuretano para a produção de oleato de etila utilizando ácido oleico e álcool etílico em sistema livre de solvente, apresentou resultados significativos com atividade de estereficação obteve $2017,12 \mathrm{U} / \mathrm{g}$, rendimento de $456,28 \%$ e conversão de 48,67 \%, apresentando simplicidade, rapidez e viabilidade no processo de imobilização, torna se um fator de particular de interesse para aplicação em processos industriais, podendo-se uma alternativa viável na aplicação em reações de esterificação.

\section{REFERENCIAS}

ABBAS H., COMEAU L. Aroma synthesis by immobilized lipase from Mucor sp. Enzyme and Microbial Technology. v. 32, n. 1, p. 589-595, 2003.

BRÍGIDA A. I. S., CALADO V. M. A., GONÇALVES L. R. B., COELHO M. A. Z. Effect of chemical treatments on properties of green coconut fiber. Carbydate Polymers. v. 79, n. 1, p. 832-838, 2010.

DALLA ROSA C., OLIVEIRA D. D., OLIVEIRA J. V. (2010). The role of organic solvent amount in the lipase-catalyzed biodiesel production. Food Science and Technology (Campinas). v. 30, n. 1, p. 76-78, 2010. 
DHEEMAN D. S., HENEHAN G. T., FRÍAS J. M. Purification and properties of Amycolatopsis mediterranei DSM 43304 lipase and its potential in flavour ester synthesis. Bioresource technology. v. 102, n. 3, p. 3373-3379, 2011.

FERRAZ L. I. R., POSSEBOM G., ALVEZ E. V., CANSIAN R. L., PAROUL N., DE OLIVEIRA D., TREICHEL H. Application of home-made lipase in the production of geranyl propionate by esterification of geraniol and propionic acid in solvent-free system. Biocatalysis and Agricultural Biotechnology. 2014.

GABELAN A.; Bioprocess Production of Flavor, Fragance, and Color Ingredientes, Wiley: New York, 1994.

GANDHI N. N., SAWANT S. B., JOSHI J. B., MUKESH D. Lipozyme deactivation by butanol and temperature. Enzyme and microbial technology. v. 17, n. 4, p. 373-380, 1995.

GUMEL A. M., ANNUAR M. S. M., HEIDELBERG T., CHISTI Y. Lipase mediated synthesis of sugar fatty acid esters. Process Biochemistry. v. 46, n. 11, p. 2079-2090, 2011.

GUNCHEVA M., TASHEV E., ZHIRYAKIVA D., TOSHEVA T., TZOKOV N., Immobilization of lipase from Candida rugosa on novel phosphorus-containing polyurethanes: application in wax ester synthesis. Process Biochem. v. 46, n.1, p. 923-930, 2011.

KUMAR R., MADRAS G., MODAK J. Enzymatic synthesis of ethyl palmitate in supercritical carbon dioxide. Journal of Industrial and Engineering Chemistry. v. 43, n. 1, p. 1568-1573, 2004.

MORRISON R. T., BOYD R. N. Organic Chemistry. v. 735, n. 1, p. 591-600, 1966.

NYARI, N. L. D., Estudo da Imobilização de Lipase de Candida antarctica B em Poliuretano. Dissertação de Mestrado em Engenharia de Alimentos da Universidade Regional Integrada do Alto Uruguai e das Missões - URI, Erechim, 2013.

PAROUL N., GRZEGOZESKI L. P., CHIARADIA V., TREICHEL H., CANSIAN R. L., OLIVEIRA V., OLIVEIRA D. Production of geranyl propionate by enzymatic esterification of geraniol and propionic acid in solvent-free system. Journal of Chemical Technology and Biotechnology. v. 85, n. 1, p. 1636-1641, 2010.

PAROUL N., GRZEGOZESKI L. P., CHIARADIA V., TREICHEL H., CANSIAN R. L., OLIVEIRA J. V., DE OLIVEIRA D. Erratum to: Solvent-free geranyl oleate production by enzymatic esterification. Bioprocess and biosystems engineering. v. 34, n. 3, p. 331-337, 2011.

RAJENDRAN A., PALANISAMY A., THANGAVELU V. Lipase catalyzed ester synthesis for food processing industries. Brazilian archives of biology and technology. v. 52, n. 1, p. 207-219, 2009.

SKORONSKI E., JOÃO J. J., CECHINEL M. A. P., FERNANDES M. Optimization of nbutyl hexanoate synthesis applying lipase immobilized (Termomyces Lanuginosus) in gelatin. Química Nova. v. 36, n. 3, p. 364-367, 2013. 